\title{
The Choice and Organization of Materials in the Communicative Minimum for Teaching Communication to Students With a Non-Humanities Profile
}

\section{SUMMARY}

The question of the activities approach to the choice and organization of materials in the communicative minimum for textbooks for teaching students with a nonhumanities profile has been researched on three levels: macro, medium and micro. The history of the choice of contents of teaching and its organization in communicative minimum are described. The recommendations to take into consideration the results of research, when choosing materials to the communicative minimum for teaching students of non-humanities profile within the limits of training well-educated and well-mannered students of nonhumanities profile have been worked out.

Keywords: content of teaching, choice of materials, types and kinds of communica- tion, forms and functions of communication, activities approach

In 1966, the minimum vocabulary for Ukrainian schoolchildren was selected by V. D. Arakin, V. M. Lubimova, I. V. Rahmanov, G. M. Uizer, S. K. Folomkina and V. S. Tsetlyn. Later on, this selection was re-edited and re-published. The suitability of the chosen lexical units for promoting the process of communication was defined indirectly, based on features such as "semantic value" and "combinability", and they were not stylistically delimited. Lexeme features like polysemy, word-formation value, suitability for forming other units and frequency were taken into account. Despite thorough scientific grounding, the modern understanding of the tasks related to teaching communi-

Bronislava Rubinska, PhD in Pedagogy, Associate Professor of the Department of European Languages, Kyiv National University of Trade and Economics, Ukraine. 


\section{Tudományos múhely}

cation requires correction in some of the principles, such as 1) the exclusion of synonyms, 2) the obligatory stylistic neutrality of the units used in education.

Further development in the theory underlying the choice and organization of language materials was implemented within the limits of the communicative approach to teaching foreign languages. It was applied to German and English by I. L. Bim (1979) and by V. D. Arakin, respectively. A distinction was made between structural and functional language models. The basis was the linguistic theory focusing on variability as the main (but not the only) difference between a phrase and a sentence, formally expressed with the help of intonation. Many other differences between a sentence and an utterance were not taken into account.

The development of structural and functional approach allowed the introduction of the level of supra-phrasal unity and text. Structural and functional types of micro-dialogues and communicative types of monologues were singled out.

The modern understanding of the term "function" does not only cover the function of a language unit, but also the speaker's function in trying to express thought more accurately and to influence the partner in communication, which enables a more complete application of the communicative approach to the teaching of foreign languages.

The application of the communicative approach to the choice and organization of materials slowly transfers this problem from the creation of vocabulary and grammar minimums to the theory of program and textbook creation. Thus the subdivision between lexis and grammar is removed, and the correlation between communicative tasks and the teaching material is applied. The necessity to correlate the language system with communication arises. But the system of teaching communication in the methods of Teaching Foreign Languages still needs improvement in terms of the content of teaching foreign languages. There is still a number of questions regarding the choice and organization of materials. These include a more exact general approach to this problem and the identification of the features of textbook material selection and organization for teaching students of non-humanities profiles. The generalization and development of the existing approaches in this research are related to the consistent consideration of all system-forming characteristics of communication on the one hand, and the use of research data in pragmalinguistics on the other, with the aim to bring foreign language teaching to high-school students of non-humanities profiles closer to their actual needs and to strengthen its educational impact. This problem is viewed from an activities approach, which makes choice more specific.

Improvement in the content of teaching foreign languages in higher education is related to successive uses of the activities approach in teaching. Students' activities have become considerably more colourful over the decades. After Ukraine's adoption of the EU system of education and has been participating in the Bologna process, students were given the opportunity to study abroad, participate in international projects, conduct scientific research and report about the results at the international conferences and symposiums. However, this analysis has shown that bachelors and masters 


\section{Tudományos múhely}

have certain difficulties in communication in some areas, including scientific fields. This is due, among others, to the fact that the question as to what to teach has been studied insufficiently.

The aim of this article is to show successive steps in the choice and organization of materials in communicative minimum in textbooks for students studying subjects other than humanities. Let us first consider the concept of "teaching content". There is no unanimity in the definition of this concept. According to the authors of the book "Contents of Teaching Foreign Languages at School", there is no exclusive answer to the question "What to teach?" (Klimentenko et al., 1984). Based on pedagogical principles and on communication theory, T. Y. Mironova gives the following interpretation of the term: construction of contents of teaching of foreign languages, which is aimed at peculiarities of communication surely corresponds to the demands of modern society. So it is necessary not only to investigate general problems of communication but also communication of every concrete group of communicating people" (Mironova, 1985). This understanding of the term was used in this research of communication by students of trade and finance. This requires the selection of a) those parameters of communication that can be introduced into the process of teaching foreign languages; b) the way they can be combined in this process; c) the correlation of super-induced parameters of real-life communication with the principles of pedagogical activity. The term "contents of teaching foreign languages" and content selection must be viewed from the perspective of communication activities, and the requirements must be set up for the choice and organization of materials in textbooks. The following tasks need to be accomplished:

- consideration of the factors which characterize the communication of BA and MSc students of finance and must be taken into account to ensure completeness of the choice of language materials and their efficacy;

- identification of language materials that provide the above mentioned characteristic features for classroom communication;

- work out the requirements to the choice and organization of language materials into a communicative minimum, that will provide communication needs of this group of students.

Firstly, the concept of "communication" has a lot of various interpretations used by scientists (Skalkin, 1983; Klimentenko et al., 1984; Passov, 1980). In Russian and Ukrainian there are two synonyms. In some works it is used in the meaning of a theory, while in others it is a synonym for communication as a discipline, and as students' language use characterized by creativity, purposefulness and interrelationship between the communicators. The polysemy of the meanings of the term is the reason for confusion. In this essay, I agree with the definitions that take communication for an exchange and transfer of information, which may be face-to-face or mediated, results in the influence of one speaker on another one.

As the various types of communication are discussed in detail in psychology, more specifically, social psychology and the theory of interaction, this research was based on their findings. The function of communication is the organiza- 


\section{Tudományos múhely}

tion of interaction, i.e. regulation of the participants' activities that fit into to their mutual or individual plans. The role of speech is the mediation of efforts at the participants' activity regulation. Partners exchange information in order to change each other's activity. In an interaction both communicators are equally active, while in the case of influence only one is active. "If the need in communication is mainly realized in the process of intercommunication by the subject of communication, in the process of influence it is different. In the latter it is the need of self-establishment, self determination of the leader. ...The aim of the process of interference is such integration of partners' activities, that can be characterized as cooperation" (Academy of Sciences of the USSR, 1983). Any interaction presupposes both reciprocity and opposition.

As the underlying processes of communication are interaction and influence, the informative nature of the communication process is not denied, but we consider it secondary in the process of serving mutual activities. The communication of the analysed students is related to their typical activities, regulated by social requirements and control on the part of their professors. These are:

a) their work during future professional activities in a bank or financial institution;

b) mutual creative activities;

c) their studies;

d) their scientific work. Thus their mutual speech activities are also reduced.

The analysis of psychological research papers and books reveal that communication is a very complex phenomenon with a hierarchal structure. Psychologists analyse communication on three levels: the highest (macro-), medium (mezo-) and the lowest (micro-) level. In this approach, students' activities can be considered on the level of activity, detailed actions and separate associated actions, if we want to identify their imminent characteristics and the selection requirements in a communicative minimum. Under "communicative minimum" we mean a set of spheres, situations (acts of speech) and a set of language units that provide their implementation. So we will start this analysis with macro level. Here we were mostly interested in communication of students with other people that can be characterized by most typical themes and spheres of communication.

The concept "sphere of communication" is also understood in various ways: psychology, linguistics and the methods of teaching foreign languages at higher school consider this expression from their own professional point of view. For the purpose of this study, I rely on the definition proposed by V. L. Skalkin (1983), based on the concept of "situation": communication is a set of situations. Various spheres are distinguished: social and domestic, family, professional, socio-cultural, social activity, law and administration, and spectacular-mass. It is not explicitly expressed, but this nomenclature can be implicitly associated with practice and the intellectual activity of communicators. Thus the spheres of communication can be considered from the perspective of student activities, and in a broad sense, the main type of activity, namely, studies and scientific work. Whichever definition is chosen, in terms of oral communication a student is the subject of the activity, or the centre of this space. This peculiarity of the term differentiates it from the concept of 
'theme', which characterizes the line segment of reality without any dependence on the speaker (Vaisburd, 1981). Thus if a student's active position in speech activity is to be defined, the sphere of communication must be taken as a starting point to consider the theme as a structural element of the situation and define the subject of the conversation.

Due to the high importance of spheres, we can propose the first requirement to the choice and organization of materials in communicative minimum: representation of the spheres of communication, typical for a student contingent, in this case, MA students of finance. As the classification of spheres proposed by V. L. Skalkin (1983) can be referred to any contingent of students, we have to specify the contingent.

Another task is to select situations within the analysed sphere. This analysis has shown that the situations proposed by the authors of textbooks stimulate only one or two types of activities: listening and speaking. However, recent trends also require consideration for the didactic principle of integration. The implementation of the integration principle and other didactic principles to prevent discrepancy between the contents of education and pedagogical reality requirements a) the singling out of the communication parameters that can be introduced into the teaching process, b) defining the way the individual parameters can be combined and integrated into simulated classroom communication; $c)$ the correlation of the introduced parameters with the principles of practical pedagogical activity.

At the intermediate level, typical student contacts must be analysed within the chosen spheres. To solve the problem we have to consider the typological characteristics of communication, namely, the types, functions and forms of communication. In classroom communication one of them can be picked to be treated as the principal one, taking the stage of education into account. Below is a description of the typological characteristics in interaction with each other.

In modern psychology different types of communication are distinguished: socially oriented, subject-oriented and interpersonal. In socially oriented communication the most typical activities performed by students of non-humanities are making public addresses, reports and short lectures, either in one's native tongue or in a foreign language. Foreign languages are mainly used for establishing business and scientific contacts with foreigners. Students are involved in the latter during classroom activities. In order to bring the process of education closer to the needs of real-life communication students need to be involved in situations where they are required to act as the subject of communication, whether initiators or organizers, in the process of interaction with other participants of activities. This means that the teaching material must be selected with consideration to socially oriented and group focus types of communication, and its functions, forms and types.

Communication focused on a group presumes joint activities performed to meet group needs, helps to organize group activities and solves the set group objectives. For MA students participation in joint activities is related to their studies, involvement in joint projects and scientific seminars, webinars, conferences and symposiums.

In psychological papers and articles it 


\section{Tudományos múhely}

is stated that subject-oriented communication is insufficiently researched. However, this research is based on characteristics such as:

1) a common goal, which unites the efforts of participants of a joint subjectoriented activity;

2) the existence of a common goal defines and differentiates specific tasks of each of its participants. It is made specific in certain tasks entrusted on each participant, and can be implemented only in line with joint actions;

3) speech acts (SA) implemented by the participants of joint activities differ from individual SAs, since they are all interconnected, each not only based on individual acts, but necessarily takes into account the presumed future acts of all other participants of the activity (assistance or counteraction). In the process of mutual activity realization the acts of its individual is regulated both by the reflection of the object it is aimed at but also the actions performed by other participants, and those changes in the object which are the result of it. The acts of an individual are thus built not only in accordance with the correspondence to the task and object. Private party "adapts" the action performed by other people. The regulation of an individual act includes the moment of "adaptation". It increases such characteristics of action as "dynamics". Finally, the evaluation of result comply with the demands that are determined by agreement of "mutuality" of joint activities (Manko, 1979).

Another aspect of this research is the study of the roles of communication. It helps to present the planned result of schooling as an ability to implement the main functions of communication.
In communication theory the following functions are distinguished: informational-communicative, regulatory-communicative and affective-communicative. In methods of teaching foreign languages these functions were defined by I. L. Bim as cognitive, regulative, value-oriented and conventional (Bim, 1979). The research presented in this essay is based on classification, and enables us to present the planned results of training. Distinctions is purely theoretical, as all these functions are interrelated in real-life communication. "Cognitive function" is seen as the process of transferring and receiving information. It is in one way or another related to people's activities focused on the conditions and means of its implementation. Even thinking processes proceed faster under condition of constant informational communication.

For students the implementation of the cognitive function correlates with their studies and can be successful if they pass credits, examinations, defend course and diploma papers. The regulatorycommunicative function is implemented in the process of behaviour, whether of the student or of someone else. "In the process of communication. In the process of communication an individual can influence the motive, aim, program, decision-taking, execution of several acts and their control, i.e on all components of his partner's activities. In this process mutual stimulation and correction of behavior is realized. This influence can be very deep and influence a personality as a whole (Vaisburd, 1981). The regulative function may be manifest in the form of a call to action or to finish an action, as in a recommendation, appeal, order, or motto. Their meaning is known to every- 


\section{Tudományos múhely}

one since childhood. Another implementation of this function is interdiction. The first thing a small child understands is impossible and possible. In their future a lot depends on how well students have understood social interdictions. The third implementation of the regulative function, destabilization, is special, as it has evolved during the history of civilization. Every human being does work in favour of or against other people. This function is used in everyday life in the form of reproach, threat and accusation.

The third function is value-orientation. It is related to the desire to communicate with friends, maintain friendly relationship, based on mutual interests, joint activities.

The fourth function is the conventional one. It is implemented according to the norms of behaviour accepted in the society where the student lives.

Under certain conditions one of the functions can become picked as the main one. For example, in a joint activity, the regulative function is the leading one, as it reflects the active position of the communicators, their intention to influence others with the aim of changing their actions and plans, and it can be implemented in the form of a call to actions, an interdiction of actions, the organization of joint actions, the correction of other participants' actions, and so on. In the process of joint activities, information is exchanged directly or via social networks, and the evaluation of results is focused on getting a regulatory effect.

The syntactic features of informational descriptive monologues include the use of homogeneous parts of the sentence, sentences with compound nominal predicates. Verbs of existence and the presence of something are used as predicates. The most typical grammar structure is introduction - a phrase introducing the subject, event, phenomenon on the whole, or the statement of its presence. This is followed by details, the characteristics of a given person, and the subject or phenomenon of reality. These are given in words and phrases that specify and clarify the concepts given in the introductory part. The end of the monologue can reassert the presence of a person, subject or phenomenon or the selected symptoms or characteristics or information about the exhaustion of the selected symptoms or characteristics. All descriptive informative dialogues should be viewed as a single structural unit consisting of elements such as 1 introduction of a phenomenon, persons, events and subjects; 2 characteristics of this phenomenon, person, event or subject, 3 generalization or concretization of the introduced characteristics.

In narrative monologues, the use of sentences with predicates of action is the most typical. Informative monologues and narrations (information, story) are organized as the transfers of successive actions. Predicates in them are expressed with the help of verbs of action, which change each other in turn, and subordinate modifiers are the words which show the time and place of action. A narrative monologue starts expressed with a phrase introducing the event or subject of the action, or the place and time of the action. The expressions of event development contain predicates reflecting certain segments of actions not accompanied by speech in time and space. The final phrase of a monologue shows either the end of these actions with the help of 


\section{Tudományos múhely}

predicate about the result of the action or a change in the place and time of the subjects of action, as expressed by subordinate modifiers of time and place in space semantics.

Thus the following characteristic features of communicative activity need to be taken into account when evaluating communicative minimum for students of non-humanities subjects:

- representation of the spheres and situations of communication, typical for the student contingent it is meant for. In this research it is meant for MA students of finance.

- suitability for all four functions of communication; tion;

- access to three types of communica-

- representation in the minimum of speech units, relating elementary text units to the detailed text.

The extent to which the units can meet the above requirements has been evaluated on the basis of their effective force potential.

\section{REFERENCES}

Academy of Sciences of the USSR (1983): Speech Communication: Problems and Perspectives. Collection of scientific analytical reviews, Academy of Sciences of the USSR, Moscow (in Russian).

Bim, I. L. (1979): Some Problems of Teaching Dialogue Speech. Foreign Languages at School, No. 5, 20-27 (in Russian).

Doroshenko, A. V. (1986): Incentive Speech Acts and their Interpretation in the Text (on the Material of the English Language). PhD Thesis in Philological Science, Moscow Institute of Foreign Languages, Moscow, 26 (in Russian).

Fastovets, R. V. (1985): Methods of Teaching Oral Foreign Language Communication at the Beginning Stage in a Language University (on the material of the English Language). PhD Dissertation in Pedagogical Science, Kyiv Institute of Foreign Languages, Kyiv, 223 (in Russian).

Karimova, L. A. (2009): Contents and Technologies of Teaching Foreign Languages in Conditions of Modernization of Higher Professional School. On the Example of Non-humanities Profile Universities Participants of the Bologna Process. PhD Thesis in Pedagogical Science, Kazan, 230.

Klimentenko, A. D. et al. (1984): Contents of Teaching Foreign Languages at School. Organization of Speech Activity. Pedagogics, Moscow (in Russian).

Kornayeva, Z. V. (1982): Organization of Teaching Dialogue Speech in the 4-5 Forms of a Secondary School (on the material of the German Language). PhD Dissertation in Pedagogical Science, Moscow Institute of Foreign Languages Moscow (in Russian).

Manko, Y. N. (1979): To the Question of Level Analysis of Social Influence on the Formation of Socially Active Position of a Pupil. Problems of Psychological Influence. Ivanovo State University of the First in Russia Ivanovo-Voznesensky City-wide Soviet of Workers' Deputies, 30-40 (in Russian).

Mironova, T. Y. (1985): Teaching Oral Expressive Speech in the Intensive Course of a Foreign Language (Problems of the Contents of Teaching). $\mathrm{PhD}$ Dissertation of Pedagogical Science, Institute of Foreign Languages, Moscow (in Russian).

Passov, Y. I. (1980): The Definition of the concept "communicative method". In: Problems of Communicative Teaching of Foreign Language Activity. Volume 208, Voronezh State Pedagogical Institute, Voronezh, 26-39 (in Russian).

Skalkin V. L. (1983): Situation, Theme and Text in Linguistic-methodological Aspect (Organization of Material for Oral Speech). Russian Language Abroad, No. 3, 52-58 (in Russian).

Vaisburd, M. L. (1981): Typology of TeachingSpeech Situations. In: Klimentenko, A. D. - Moskalska, O. I. (eds.): Psychologicalpedagogical Problems of Teaching Foreign Languages. Research Institute of Contents and Methods of Teaching of the Academy of Pedagogical Science of the USSR, Moscow, 8191 (in Russian). 